\title{
ANTIOXIDATIVE ACTIVITY AND PHYTOCHEMISTRY PROFILE OF HIBISCUS SABDARIFFA HERB EXTRACTS
}

\author{
QOTRUNNADA FITROTUNNISA ${ }^{1}$, ADE ARSIANTI ${ }^{2,3^{*}}$, NADZILA ANINDYA TEJAPUTRI ${ }^{1}$, FONA QORINA ${ }^{1}$
}

1Medical Student, Faculty of Medicine, Universitas Indonesia, ${ }^{2}$ Department of Medical Chemistry, Faculty of Medicine, Universitas Indonesia, ${ }^{3}$ Drug Development Research Cluster, Indonesia Medical Education and Research Institute (IMERI), Faculty of Medicine, Universitas Indonesia

Email: arsi_ade2002@yahoo.com

Received: 11 Dec 2018, Revised and Accepted: 10 Mar 2019

ABSTRACT

Objective: Hibiscus sabdariffa, known as Roselle, is a widely-cultivated herb in Indonesia and has been consumed as an herbal drink due to its medicinal properties. The purpose of this research is to identify the antioxidant activity and phytochemical profile of Hibiscus sabdariffa.

Methods: The Hibiscus sabdariffa samples were extracted and macerated with three different organic solvents: ethyl acetate, ethanol, and n-hexane. These extracts were then analyzed using thin layer chromatography (TLC) and phytochemical tests to identify the extracts' secondary metabolites. The extracts' antioxidant activity was evaluated using the 2,2-diphenyl-1-picrylhydrazyl (DPPH) method.

Results: The phytochemistry tests were positive for glycosides, alkaloids, steroids, triterpenoids, tannins, and flavonoids. The TLC analysis revealed that the extracts containing two to three organic compounds. The ethanol Hibiscus sabdariffa extracts with an IC 50 value 103.63 ppm showed stronger antioxidant activity than the ethyl acetate extract.

Conclusion: Ethanol Hibiscus sabdariffa extracts may be a potential source of natural antioxidant.

Keywords: Antioxidant, DPPH, Hibiscus sabdariffa; IC $_{50}$, Phytochemical

(C) 2019 The Authors. Published by Innovare Academic Sciences Pvt Ltd. This is an open access article under the CC BY license (http://creativecommons. org/licenses/by/4. 0/) DOI: http://dx.doi.org/10.22159/ijap.2019.v11s6.33532

\section{INTRODUCTION}

Antioxidants protect the human body against free radicals, especially reactive oxygen species (ROS) [1]. ROS, which are products of the metabolism process, can be found in all living cells, such as the respiratory chain in the mitochondria. UV lights, pollutants, radiation, xenobiotic, and bugs are the most common sources of extracellular ROS [1]. Several typesof ROS exist, including hydrogen peroxide, superoxide anion radicals, reactive hydroxyl radicals, singlet oxygen, hypochlorite radicals, nitric oxide radicals, and lipid oxide radicals $[1,2]$. ROS are not harmful in controlled amounts, but if the production of ROS exceeds endogenous antioxidants which produces within the body, oxidative stress will occur and may lead to DNA mutation and protein denaturation and affect carbohydrate and lipid metabolism [1]. Oxidative stress is also associated with the etiology of many diseases, such as cancer, arthritis, cardiovascular disease, and diabetes [1]. Therefore, maintaining a balance between antioxidant levels and ROS is vital [3]. Antioxidants may interfere with ROS in many ways, such as scavenging free radicals, protecting cells from lipid peroxidation-induced damage, inhibiting malondialdehyde formation, protecting the cell from fft-BHP-induced damage, inhibiting thiobarbituric acid formation, and reducing glutathione depletion [4]. The flavonoid action mechanism interferes with ROS and quenches free radicals by chelating metals, stimulating antioxidant enzymes, and releasing a hydrogen atom that suppresses the enzymes that lead to free radical formation [1].

There are two classes of antioxidants, natural and synthetic antioxidants. Natural antioxidants are preferred because synthetic antioxidants produce substances that have a carcinogenic effects [5] Moreover, natural antioxidants can be easily found in all plant parts [4]. Therefore, research concerning natural antioxidants from plants has intensified. For example, Hibiscus sabdariffa, commonly known as Roselle and part of Malvaceae family, and is widely cultivated in tropical and subtropical countries (i.e., Indonesia) [4]. Roselle calyces are consumed in herbal drinks, jam, pudding, teas, gelatin, and cake [4]. Roselle has been consumed as an herbal drink due to its medicinal properties; it has anti-inflammatory, antibacterial, antipyretic, antifungal, antinociceptive, antiparasitic, hepatoprotective, nephroprotective, and diuretic effects due to its potent antioxidants, including anthocyanins, flavonoids, organic acids, and polysaccharides [4]. The amount of antioxidants in Hibiscus sabdariffa plants varies based on environment, ecology, variety, genetics, and harvest conditions [4]. The Hibiscus sabdariffa antioxidants may be used as anticancer therapies due to their cytotoxicity [4]. For example, the protocatechuic acid, polyphenol, and anthocyanin in Roselle extracts has an apoptotic effect on cancer cell lines, reduces carcinogenic action, and inhibits tumour metastasis in tissue [4].

Therefore, the purpose of this research is to evaluate the phytochemical profile and antioxidant activity of Hibiscus sabdariffa extracts. The Hibiscus sabdariffa sample was extracted and macerated in three different solvents: ethyl acetate, ethanol, and n-hexane. Then, the antioxidant activity was evaluated using the DPPH method. Finally, the extract was analyzed using a phytochemistry test and thin layer chromatography to identify its organic compounds.

\section{MATERIALS AND METHODS}

\section{Extraction of Hibiscus sabdariffa samples}

The Hibiscus sabdariffa flowers were purchased in a local market, the AEON Mall, in Serpong. The flowers were dried, ground, and immersed in a container with three different solvents: ethyl acetate, ethanol, and n-hexane. The maceration process was done in stages. First, the flowers were macerated into $500 \mathrm{ml}$ of the first solvent (nhexane) for $24 \mathrm{~h}$. Then, they were filtered and the solid filtrate was macertated into $500 \mathrm{ml}$ of the second solvent (ethyl acetate). After filtration, the solid filtrate was macerated into $500 \mathrm{ml}$ of the third solvent (ethanol). Subsequently, liquid filtrate of n-hexane, ethyl acetate and ethanol respectively, were concentrated using a vacuumdrying process in a rotary evaporator for $12-48 \mathrm{~h}$.

\section{Antioxidant analysis}

The DPPH (2.2-diphenyl-1-picrylhydrazyl) method was used to determine the Hibiscus sabdariffa extract's antioxidant activity. The ethanol extracts in five different concentration $(3.75 ; 6.25 ; 12.5 ; 25$; 50) and $100 \mu \mathrm{L}$ ethyl acetate were placed into a microcentrifuge tube. Then, $2.9 \mathrm{ml}$ of the DPPH molecule at a $0.004 \%$ concentration in $0.75 \%$ methanol were added to the sample tube, positive control 
tube, and blank tube. All the tubes were incubated in the dark at room temperature for $60 \mathrm{~min}$. The absorbance was read using 517 $\mathrm{nm}$ wave spectrophotometry. The percentage of DPPH inhibition was calculated using the following formula:

Percentage of DPPH inhibition

$=\frac{\text { (The absorbance of blank }- \text { the absorbance of a sample) }}{\text { The absorbance of blank }} \times 100 \%$

Where the absorbance of the blank refers to the absorbance of the DPPH without the added sample and the absorbance of the sample refers to the absorbance of the DPPH with the added sample.

\section{Thin layer chromatography}

Thin layer chromatography (TLC) was used to determine the number of organic compounds in the extract. This method separated the organic compound in the sample based on polarity. A thin plate was coated with an inert material, such as silica gel is used as a stationary phase. The mobile phase is a mixture of chloroform $\left(\mathrm{CHCl}_{3}\right)$ and methanol $\left(\mathrm{CH}_{3} \mathrm{OH}\right)$ in ratio $4: 1$, which was placed inside the chamber. Sample were prepared by diluted the extracts $0.5 \mathrm{ml}$ of methanol. The sample was applied to the TLC plate by using a capillary pipette. It was then dried and placed on the mobile phase in chamber. Chemical compounds containing in the sample migrated and eluted at different rates based on its polarity. After completion, spots of chemical compound in the TLC plate was visualized by UV lamp at the wavelength of $254 \mathrm{~nm}$. The compound was identified based on the retention factor ( $\mathrm{Rf}$ ) of its spot. The retention factor is a parameter for interpretation of the migrated sample, which represent the position of the spot in the stationary phase after elution. The $\mathrm{Rf}$ formula is as follows:

$$
\mathrm{Rf}=\frac{\text { Distance moved by sample }}{\text { Distance moved by solvent }}
$$

\section{Phytochemical test}

Phytochemical tests were used to determine secondary metabolites, such as glycoside, alkaloid, steroid, triterpenoid, saponin, tannin, and flavonoid, containing in the Hibiscus sabdariffa extracts. The test procedures for each metabolite are the following:

\section{Glycoside test}

The glycosides test was conducted by evaporating $0.1 \mathrm{ml}$ of the Hibiscus sabdariffa ethanol, ethyl acetate, and n-Hexane extracts separately, over a water bath. The remaining solution was diluted in $5 \mathrm{ml}$ of acetic acid anhydrate. Then, 10 drops of concentrated sulfuric acid were added. The formation of a blue or green product indicated a positive result for glycosides.

\section{Alkaloid test}

The alkaloid test was conducted by evaporating the solution in a porcelain cup. The residue was diluted in $5 \mathrm{ml}$ of $2 \mathrm{~N} \mathrm{HCl}$. Then, it was divided it into three tubes. The first tube was the blank, and it was mixed with $2 \mathrm{~N} \mathrm{HCl}$. Three drops of a Dragendorff reagent were added to the second tube. Then, three drops of a Mayer reagent were added to the third tube. The formation of a yellow precipitate in the third tube and orange precipitate in the second tube indicated that the solution was positive for alkaloids.

\section{Steroid and triterpenoid test}

The Liebermann-Burchard reaction was used in the steroid and triterpenoid test. This test was conducted by evaporating $2 \mathrm{ml}$ of the solution in a porcelain cup. The residue was then diluted in $0.5 \mathrm{ml}$ of chloroform $\left(\mathrm{CHCl}_{3}\right)$ and $0.5 \mathrm{ml}$ of anhydrate acetic acid. Then, $2 \mathrm{ml}$ of concentrated sulfuric acid was added through the tube wall. The presence of steroids was indicated by the formation of a blue-green ring, whereas the presence of triterpenoids was indicated by the formation of a violet or brownish ring.

\section{Saponin test}

The saponin test was conducted by adding $10 \mathrm{ml}$ of the solution to a tube. The tube was then shaken vertically for approximately 10 seconds. For the next 10 seconds, the tube was kept in a standing position. If the solution was positive for saponin, the presence of stable foam formation around $1-10 \mathrm{~cm}$ in height was visible for less than $10 \mathrm{~min}$. The addition of 1 drop of $2 \mathrm{~N} \mathrm{HCl}$ was used in the confirmation test as it showed that the foam still existed.

\section{Tannin test}

The tannin test was conducted by dissolving $1 \mathrm{ml}$ of the Hibiscus sabdariffa extracts in a solution of $10 \%(\mathrm{~b} / \mathrm{v})$ of $\mathrm{FeCl}_{3}$. A greenishblack or dark blue color indicated the presence of tannin.

\section{Flavonoid test}

Flavonoid screening was conducted by evaporating $1 \mathrm{ml}$ of the solution in a porcelain cup until it was dry. The remaining solution was moistened with acetone and mixed with smooth oxalic acid and boric acid powder. The porcelain cup was heated at boiling temperature (80 ${ }^{\circ}-100^{\circ} \mathrm{C}$ ) in a water bath. Then, the residue was mixed with $10 \mathrm{ml}$ of ether. The porcelain cup was read under a $365 \mathrm{~nm}$ UV light. The presence of a yellow fluorescence indicated a positive result.

\section{RESULTS AND DISCUSSION}

\section{Antioxidant activity OF Hibiscus sabdariffa}

The DPPH (2.2-diphenyl-1-picrylhydrazyl) method was used to analyze the antioxidant activity of the Hibiscus sabdariffa extracts. This method has been widely used to evaluate antioxidant activity due to its simplicity, low cost, and efficiency [6]. The presence of antioxidants may reduce the DPPH by binding a hydrogen atom from the antioxidant and a nitrogen atom from the DPPH [4]. The effect of the antioxidant is evident when the original violet color of the DPPH changes to yellow [6]. The absorption of the DPPH is monitored using a $517 \mathrm{~nm}$ UV light [6]. In this work, non-polar n-hexane extract of Hibiscus sabdariffa was not evaluated its antioxidant activity by DPPH because it cannot dissolved well in DPPH reagent, therefore polar and semipolar extracts such as ethanol and ethylcetate extract are more suitable to be analyzed by DPPH method [7].

The DPPH method uses the half maximal inhibitory concentration $\left(\mathrm{IC}_{50}\right)$ value as a parameter for interpretation of antioxidant activity. $\mathrm{IC}_{50}$ represents the concentration of substrate (extract) that reduces the DPPH activity by $50 \%$ [6]. $\mathrm{IC}_{50}$ value is inversely proportional to the antioxidant activity, so the lower IC $_{50}$ value of the substrate or extract, the higher its antioxidant activity [6]. The results of antioxidant activity evaluation of Hibiscus sabdariffa extracts are summarized in table 1.

Table 1: Antioxidant activity of the Hibiscus sabdariffa ethanol extract

\begin{tabular}{lll}
\hline Concentration (ppm) & \% Inhibition & Standard deviation \\
\hline 3.75 & 2.8 & 0.0326 \\
6.25 & 3.7 & 0.0173 \\
12.5 & 7.9 & 0.0011 \\
25 & 15.1 & 0.0142 \\
50 & 24.1 & 0.0085 \\
\hline
\end{tabular}

The linear equation that represented the relationship between the $\mathrm{IC}_{50}$ value and the concentration of the Hibiscus sabdariffa ethanol extract is $y=0.4668 x+1.6261$ and $R^{2}=0.984$. Fig. 1 illustrates the relationship between the percentage of DPPH activity inhibition and the concentration of the Hibiscus sabdariffa ethanol extract. The $\mathrm{x}$ axis in the graph represents the concentration of the ethanol extract required to reduce the DPPH activity by $50 \%$, while the $y$-axis represents the $\mathrm{IC}_{50}$ value. 


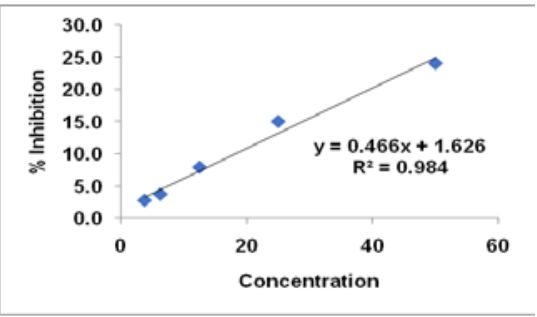

Fig. 1: The relationship between the percentage of inhibition and concentration of the Hibiscus sabdariffa ethanol extracts
Based on the results, none of the concentrations that were analyzed achieved a $50 \%$ inhibition of the DPPH activity. However, the IC $_{50}$ value of the ethanol extract can be calculated using the linear equation $y=0.4668 x+1.6261$, where the $y$-axis represents the percentage of DPPH activity inhibition and the $\mathrm{x}$-axis represents the concentration of the ethanol extract. Therefore, the $\mathrm{IC}_{50}$ value required to inhibit $50 \%$ of the DPPH activity in the ethanol extract was 103.63 , which suggests moderate antioxidant activity. The percentage of inhibition in the highest extract concentration, $50 \mu \mathrm{g} / \mathrm{ml}$, was $24.1 \%$.

The ethyl acetate extract test results are summarized in table 2 .

Table 2: The antioxidant activity of Hibiscus sabdariffa ethyl acetate extract

\begin{tabular}{lll}
\hline Concentrations (ppm) & \% Inhibition & Standard deviation \\
\hline 3.75 & 1.1 & 0.0109 \\
6.25 & 3.6 & 0.0106 \\
12.5 & 3.7 & 0.0065 \\
25 & 7.5 & 0.0457 \\
50 & 11.8 & 0.0018 \\
\hline
\end{tabular}

The linear equation that represents the relationship between the $\mathrm{IC}_{50}$ value and the concentration of the Hibiscus sabdariffa ethyl acetate extract is $\mathrm{y}=0.2163 \mathrm{x}+1.3277$, where $\mathrm{R}^{2}=0.9594$. The $\mathrm{x}$-axis represents the concentration of the ethyl acetate extract required to inhibit $50 \%$ of the DPPH activity, while the y-axis represents the $\mathrm{IC}_{50}$ value. Fig. 2 illustrates the relationship between the percentage of DPPH activity inhibition and the Hibiscus sabdariffa ethyl acetate extract concentration.

The IC $\mathrm{C}_{50}$ value of the ethyl acetate extract can be calculated using the linear equation $y=0.2163 x+1.3277$, where the $y$-axis represents the percentage of DPPH activity inhibition and the $\mathrm{x}$-axis represents the concentration of the ethyl acetate extract. Therefore, the $\mathrm{IC}_{50}$ value of ethyl acetate extract that is required to inhibit $50 \%$ of the DPPH activity is 225.02, which indicates that ethyl acetate extract of Hibiscus sabdariffa has a weak antioxidant activity. The percentage of inhibition at the highest extract concentration $(50 \mu \mathrm{g} / \mathrm{ml})$ was $11.8 \%$.

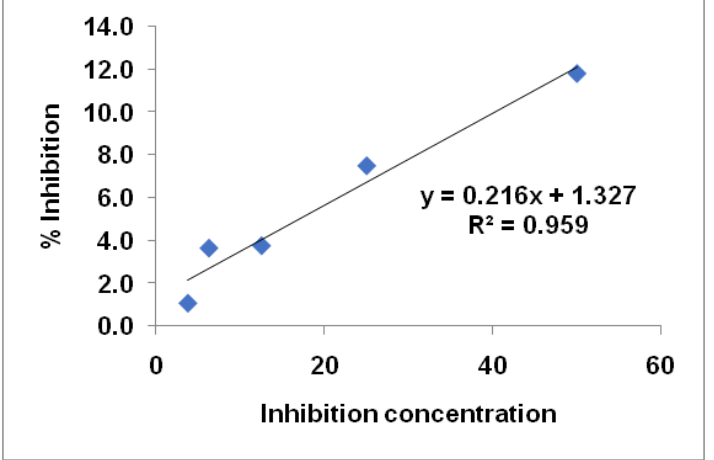

Fig. 2: The relationship between the percentage of inhibition and the Hibiscus sabdariffa ethyl acetate extract concentration

Table 3: A comparison of the IC ${ }_{50}$ values of the Hibiscus sabdariffa ethyl acetate and ethanol extracts

\begin{tabular}{ll}
\hline Extract & IC $_{\mathbf{5 0}}$ value (ppm) \\
\hline Ethyl acetate & 225.02 \\
Ethanol & 103.63 \\
\hline
\end{tabular}

The $\mathrm{IC}_{50}$ values are separated into four levels: very strong, strong, moderate, and weak. An $\mathrm{IC}_{50}$ value below 50 ppm indicates very strong antioxidant activity, an $\mathrm{IC}_{50}$ value of $50-100 \mathrm{ppm}$ indicates strong antioxidant activity, an IC 50 value of 101-150 ppm indicates moderate antioxidant activity, and an $\mathrm{IC}_{50}$ value above $150 \mathrm{ppm}$ indicates weak antioxidant activity.[8]Therefore, the Hibiscus sabdariffa ethanol extract had stronger antioxidant activity than the ethyl acetate extract as the ethanol extract had moderate antioxidant activity, while the ethyl acetate extract had weak antioxidant activity.

The results from the current study are different from previous research, in which the etanol extract of Hibiscus sabdariffa had a low
IC $_{50}$ value of $46,13 \pm 3,37 \mathrm{ppm}$, indicated a strong antioxidant activity [9]. The differences may be the result of many factors, including the different varieties of the flowers, genetics, the environment of the plant; the choice of solvent; and the solubility of the product [1]. Ethyl acetate is typically used to extract terpenoids, flavonoids, and alkaloids, while ethanol is typically used to extract polyphenols, saponins, flavanols, and alkaloids [10].

\section{Thin layer chromatography}

The retention factor (Rf) value and TLC results of the Hibiscus sabdariffa extracts are displayed in table 4 and fig. 3 , respectively.

Table 4: The retention factor (Rf) of n-hexane, ethanol of the Hibiscus sabdariffa

\begin{tabular}{lllll}
\hline Extract & Rf value & & & \\
\cline { 2 - 5 } & $\mathbf{1}$ & $\mathbf{2}$ & $\mathbf{3}$ & $\mathbf{4}$ \\
\hline n-Hexane & 0.143 & 0.571 & 0.742 & 0.914 \\
Ethanol & 0.114 & 0.571 & 0.742 & 0.857 \\
Ethyl Acetate & 0.228 & 0.543 & 0.721 & 0.942 \\
\hline
\end{tabular}




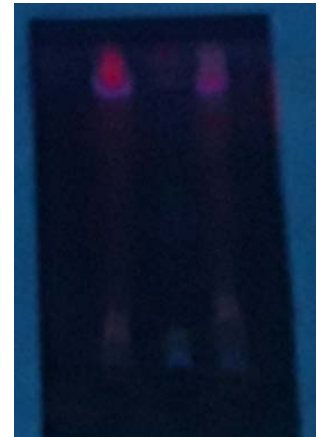

Fig. 3(a): The TLC results of the Hibiscus sabdariffa n-Hexane, ethanol, and ethyl acetate extract
The TLC analysis was used to qualitatively identify the number of organic compounds in the Hibiscus sabdariffa extracts. The analysis revealed that n-hexane and ethyl acetate extracts contain four spots of chemical compounds, while the ethanol extract contains five spots of chemical compounds. The n-hexane and ethanol extracts had two similar spots with the same Rf values, 0.571 and 0.742 . However, further study can be conducted to evaluate the specific organic compounds. For example, to evaluate the presence of flavonoids, ammonia may be sprayed on the plate, and the test results may be read under a $366 \mathrm{~nm}$ UV light. A blue colored notch at Rf 0.54 and 0.92 indicates a positive result [11].

\section{PHYTOCHEMICAL PROFILE}

The phytochemical profile of Hibiscus sabdariffa is summarized in table 5 .

Table 5: The phytochemical composition of Hibiscus sabdariffa

\begin{tabular}{llll}
\hline Metabolites & Solvent & Ethyl Acetate & N-Hexane \\
\cline { 2 - 4 } & Ethanol & + & + \\
\hline Glycoside & - & + & + \\
Alkaloid & - & - & + \\
Steroid & - & - & - \\
Triterpenoid & + & + & - \\
Saponin & - & + & + \\
Tannin & + & + & + \\
Flavonoid & + & \\
\hline
\end{tabular}

The phytochemistry test for the Hibiscus sabdariffa extracts showed that the sample was positive for glycosides, alkaloids, steroid, triterpenoid, tannin, and flavonoids. Only the ethyl acetate and nHexane extracts were positive for glycosides, alkaloids, and steroids. Triterpenoid is only present in the ethanol extracts, whereas tannin is present in the ethanol and ethyl acetate extracts. Flavonoids are present in all the extracts. The results agree with several previous studies that found that Hibiscus sabdariffa mostly contains flavonoids, anthocyanins, and polyphenolic acids [12].

Flavonoids are compounds extracted from the plant that form the aroma and color of the flowers; they can be found in several parts of a plant [13]. The subclasses of the flavonoids contained in the Hibiscus sabdariffa are as follows: quercetin, hibiscitrin, chlorogenic acid, luteolin, gossypitrin, protocatechuic acid, gossytrin, eugenol, pelargonic acid, and sterols [1]. Flavonoids have many benefits in human health due to several mechanisms, including scavenging free radicals. Flavonoids react with and stabilize radical compounds, making them less radical, through direct and indirect pathways. For example, rutin and epicatechin have inhibitory properties that affect the XO enzyme $[12,13]$. This study is limited to the qualitative measurement of secondary metabolites.

\section{CONCLUSION}

The Hibiscus sabdariffa ethanol extracts showed potent antioxidant activity and had many organic compounds. Therefore, Hibiscus sabdariffa may be used as a natural antioxidant and developed as a therapeutic alternative for cancer and inflammatory disease. Further study should evaluate the specific amount and type of antioxidants and their therapeutic applications.

\section{ACKNOWLEDGMENT}

This article was presented at The $3^{\text {rd }}$ International Conference and Exhibition on Indonesian Medical Education and Research Institute (ICE on IMERI 2018), Faculty of Medicine, Universitas Indonesia, Jakarta, Indonesia. We express our gratitude to Directorate of Research and Public Service (DRPM), University of Indonesia for the Publikasi Internasional Terindeks Scopus Untuk Tugas Akhir Mahasiswa (PITTA) research grant, fiscal year 2018. We thank the $3^{\text {rd }}$ ICE on IMERI Committee who had supported the peer review and manuscript preparation before submitting to the journal.

\section{AUTHORS CONTRIBUTIONS}

All the authors have contributed equally

\section{CONFLICT OF INTERESTS}

The authors declare no conflict of interest in this study

\section{REFERENCES}

1. Banjarnahor SDS, Artanti N. Antioxidant propert1ies of flavonoids. Med J Indones 2014;23:239-40.

2. Kumar S. The importance of antioxidant and their role in pharmaceutical science-a review. Asian J Res Chem Pharm Sci 2014;1:30.

3. Shebis Y, Iluz D, Kinel Tahan Y, Dubinsky Z, Yehoshua Y. Natural antioxidants: function and sources. Food Nutr Sci 2013;4:643.

4. Da-Costa-Rocha I, Bonnlaender B, Sievers H, Pischel I, Heinrich M. A phytochemical and pharmacological review. Food Chem 2014;165:427-34.

5. Butnario M, Grozea I. Antioxidant (antiradical compounds). J Bioequivalence Bioavailability 2012;4:1-3.

6. Kedare SB, Singh RP. Genesis and development of DPPH method of antioxidant assay. J Food Sci Technol 2001;48:412-22.

7. Barchan A, Bakkali M, Arakrak A, Pagan R, Laglaoui A. The effects of solvents polarity on the phenolic contents and antioxidant activity of three mentha species extracts. Int J Curr Microbiol Appl Sci 2014;3:399-412.

8. Muawanah, Ahmad A, Natsir H. Antioxidant activity and toxicity polysaccharide extract from red algae eucheuma cottonii and eucehuma spinosum. Marina Chim Acta 2016;17:20.

9. Kumar M, Garg R, Garg R. Phytochemical properties and antioxidant activity of hibiscus sabdariffa linn. Int J Pharm Chem Sci 2012;1:1236-40.

10. Jadid N, Hidayati D, Hartanti SR, Arraniry BA, Rachman RY, Wikanta W. Antioxidant activities of different solvent extracts of Piper retrofractum Vahl. using DPPH assay. AIP Conf Proc 2017;1854:020019.

11. Marliana SD, Suryanti V, Suyono. Skrining fitokimia dan analisis kromatografi lapis tipis komponen kimia buah labu siam (sechiumedulejacq. swartz.) dalam ekstrak etanol. Biofarmasi 2005;3:30-31.

12. Formagio ASN, Ramos DD, Ramalho SR, Silva MM, Zarate NAH, Foglio MA, et al. Phenolic compounds of hibiscus sabdariffa and influence of organic residues on its antioxidant and antitumoral properties. Braz J Biol 2015;75:70.

13. Panche AN, Diwan AD, Chandra SR. Flavonoids: an overview. J Nutr Sci 2016;5:8. 